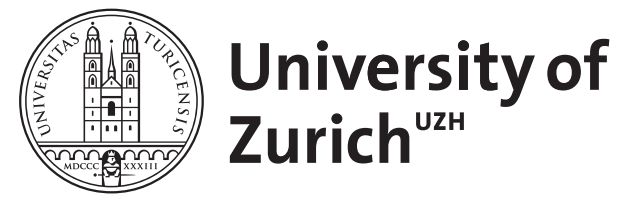
Archive

University of Zurich

University Library

Strickhofstrasse 39

CH-8057 Zurich

www.zora.uzh.ch

Year: 2020

Relative brain size is predicted by the intensity of intrasexual competition in frogs

Mai, Chun Lan ; Liao, Wen Bo ; Lüpold, Stefan ; Kotrschal, Alexander

DOI: https://doi.org/10.1086/709465

Posted at the Zurich Open Repository and Archive, University of Zurich

ZORA URL: https://doi.org/10.5167/uzh-187174

Journal Article

Accepted Version

Originally published at:

Mai, Chun Lan; Liao, Wen Bo; Lüpold, Stefan; Kotrschal, Alexander (2020). Relative brain size is predicted by the intensity of intrasexual competition in frogs. The American Naturalist, 196(2):169-179. DOI: https://doi.org/10.1086/709465 


\section{Relative brain size is predicted by the intensity of intrasexual competition in}

\section{frogs}

Chun Lan Mai (麦春兰) $)^{1,2,3}$, Wen Bo Liao (廖文波) ${ }^{1,2,3, *}$, Stefan Lüpold ${ }^{4 \S}$, Alexander Kotrschal $^{5 \S}$

${ }^{\S}$ These authors contributed equally to the project and manuscript preparation.

1: Key Laboratory of Southwest China Wildlife Resources Conservation (Ministry of Education), China

West Normal University, Nanchong, 637009, Sichuan, China

2: Key Laboratory of Artificial Propagation and Utilization in Anurans of Nanchong City, China West

Normal University, Nanchong, Sichuan, 637009, China

3: Institute of Eco-adaptation in Amphibians and Reptiles, China West Normal University, Nanchong,

637009, Sichuan, China

4: Department of Evolutionary Biology and Environmental Studies, University of Zurich,

Winterthurerstrasse 190, 8057 Zurich, Switzerland

5: Zoological Institute, Stockholm University, 10691, Stockholm, Sweden

*Correspondence: Liaobo_0_0@126.com

Running title: Larger brains through strong mate competition

MS type: article

Keywords: anurans; cognitive abilities; operational sex ratio; spawning-site group size; male-male competition 


\section{AbSTract}

Competition over mates is a powerful force shaping trait evolution. For instance, better cognitive abilities may be beneficial in male-male competition and thus be selected for by intrasexual selection. Alternatively, investment in physical attributes favoring male performance in competition for mates may lower the resources available for brain development, and more intense male mate competition would coincide with smaller brains. To date, only indirect evidence for such relationships exists and most studies are heavily biased towards primates and other homoeothermic vertebrates. We tested the association between male brain size (relative to body size) and male - male competition across $N=30$ species of Chinese anurans. Three indicators of the intensity of male mate competition-operational sex ratio (OSR), spawning-site density and male forelimb muscle mass - were positively associated with relative brain size, whereas the absolute spawning-group size was not. The relationship with the OSR and male forelimb muscle mass was stronger for the male than the female brains. Taken together, our findings suggest that the increased cognitive abilities of larger brains are beneficial in male-male competition. This study adds taxonomic breadth to the mounting evidence for a prominent role of sexual selection in vertebrate brain evolution. 
两栖动物雄性间配偶竞争强度预测脑大小变异

\section{摘要 :}

争夺配偶是动物性状进化的强有力驱动者。例如, 良好的认知能力有利于雄性个体赢得配 偶竞争，从而被性选择所青睐。另一方面，如果雄性分配更多能量到那些有利于其获得配 偶的身体性状, 他们将减少用于脑发育的能量投入; 由此推测, 更激烈的配偶竞争将使得 雄性拥有更小的脑。目前，支持这一预测的证据是间接的，且多集中在灵长类以及其他恒 温动物。使用 30 种来自中国的无尾两栖类，我们检验了雄性脑大小 (相对于身体大小) 与雄性间配偶竞争强度的关系。结果表明, 相对脑大小与三个雄性配偶竞争强度指标, 即 有效性比、产卵点密度和雄性前臂肌肉重，显著正相关，而与产卵地群体大小无关。我们 还发现，雄性脑大小与有效性比和前臂肌肉重的相关性明显强于雌性。总之，我们的发现 表明, 大的脑，这意味着更好的认知能力，在雄性间配偶竞争中是有利的。我们的发现也 在类群上拓展了性选择在脊椎动物脑进化中所起的突出作用。 


\section{Introduction}

When males compete for access to females, their precopulatory tactics of mate competition can involve scramble polygyny, contest behavior and endurance (Andersson 1994). While it is well established that body size, weaponry, or other attributes of physical strength are advantageous during such contests (Emlen 2008; Lüpold et al. 2014, 2017; Buzatto et al. 2015; McDonald et al. 2017; McCullough et al. 2018), the fitness consequences of complex, cognitively demanding behavioral strategies are relatively poorly understood.

The role of sexual selection (Jacobs 1996; Madden 2001; Garamszegi et al. 2005; Lindenfors et al. 2007), and of mate choice in particular (Boogert et al. 2011), in brain evolution has recently been addressed. Associated cognitive abilities can be advantageous when choosing an adequate mate (Corral-López et al. 2017; Chen et al. 2019). Miller (2000) argued that humans evolved such large brains because the increased cognitive abilities associated with large brains are attractive to females. For males, relatively larger brains and better cognitive abilities can likewise lead to better mate choice decisions (Corral-López et al. 2018), but whether this extends to malemale competition remains unclear.

According to the 'cognitive buffer hypothesis' (CBH), increased cognitive abilities provided by a larger brain can facilitate appropriate behavioral responses towards complex socioecological challenges (Allman 2000). When extending this hypothesis to scramble-competition polygyny, where males gain access to females by more efficient mate searching rather than defeating rivals in dyadic contests (Emlen and Oring 1977; Wells 1977), it is conceivable that greater cognitive flexibility would confer a competitive advantage. For example, individuals could learn and 
remember which behaviors are most advantageous in a given situation and flexibly adopt the one with the most promising outcome. A similar argument could be made for contest behavior. For instance, staged contests of male guppies (Poecilia reticulata) selected for relatively large or small brain size, respectively, have demonstrated that although brain size does not determine the winner, large-brained males show 'better' losing behavior by conceding faster when defeat seems inevitable (van der Bijl et al. 2018). Consequently, there is potential for brain size to impact the dynamics of male-male competition, but empirical evidence is largely lacking.

If cognitive abilities generally play an important role during mate competition, we would expect to find positive associations between, for instance, the intensity of mate competition and brain size across populations or species. Yet, a recent comparative study in pinnipeds found a negative association between relative brain size and sexually selected traits (Fitzpatrick et al. 2012). At first glance, this result seems to contradict our argument, but closer examination of the relationship reveals that this apparent trade-off between sexual traits and brain mass is driven by selection for increased body mass rather than by an actual reduction in male brain size.

Despite their cognitive advantages (Kotrschal et al. 2013; Benson-Amram et al. 2016; Buechel et al. 2018; Mai and Liao 2019), large brains come at a cost, considering that the running costs per unit mass can be 8-10 times higher for the brain than for skeletal muscles (Mink et al. 1981). These costs were used to explain apparent constraints on brain size evolution in the context of sexual selection, as the development of costly sexual traits may limit the energy available for the development of the large brain. Indeed, some studies have found inverse relationships between brain size and investments in postcopulatory sexual traits like testes mass (Pitnick et al. 2006; 
Gonzalez-Voyer and Kolm 2010; Fitzpatrick et al. 2012), whereas others have not (Schillaci

2006; Lemaitre et al. 2009; García-Peña et al. 2013). How brain size associates with

precopulatory mate competition, however, is unknown. The role of mate competition in brain size evolution therefore remains enigmatic and requires further empirical investigation.

The anurans are a suitable system to study the links between mate competition and brain evolution since several species show a similar mating system but vary in their intensity of male mate competition. Although a recent comparative study suggested little impact of mating system (single-male vs. multiple-male amplexus), relative testes size or the way that males access females (attracting them with calls or searching for them) on the evolution of anuran brain size (Zeng et al. 2016), these results do not reject a possible role of premating sexual selection. For example, rather than measuring variation in male-male competition, the crude distinction of attracting females by calling versus searching for them largely reflects two different strategies of accessing mates, each of which could apply to a spectrum of sexual selection intensities. Further, both the presence/absence of multi-male amplexus and variation in testes size focus more on the degree of postcopulatory sexual selection than the extent of premating male-male competition. In fact, single-male amplexus could result from both a truly monogamous mating system and intense premating sexual selection with some males successfully controlling access to females. Thus, the marked interspecific variation in the density of breeding individuals and their operational sex ratio are likely to capture more nuanced differences in premating sexual selection, and male-male competition in particular, than the variables used by Zeng et al. (2016). 
Theory predicts that as the number of breeding males increasingly exceeds that of available breeding females, intrasexual selection should intensify (Emlen and Oring 1977). Further, denser breeding populations are predicted to have a higher rate of mate encounters, resulting in more mating opportunities (Kokko and Rankin 2006), but that they alsoincrease the likelihood of encountering rival males (Emlen and Oring 1977; Knell 2009). Since more frequent male encounters reduce the efficacy of dyadic contests in controlling access to females (Parker et al. 2013; Lüpold et al. 2014, 2017), male-male competition might increasingly shift toward scramble competition, alternative mate-acquisition strategies (e.g., mate interception), or from pre- to postmating sexual selection. Consequently, variation in the breeding density and operational sex ratio could influence both the overall intensity and the form of sexual selection. If male cognitive ability and thus relative brain size (or the size of relevant brain regions) confers any fitness benefits in situations of intrasexual selection, particularly where strategic behavior is essential, brain evolution should respond to variation in the social environment and associated form and intensity of male-male competition.

Although a direct interspecific link between brain size and cognitive ability remains to be studied in anurans, there is substantial indirect evidence to suggest that such a link is likely to exist. For example, brain size is positively associated with several aspects of cognition in fishes (Kotrschal et al. 2013, 2014, 2015). Similarly, species with relatively larger brains show higher levels of behavioral flexibility and innovativeness in both birds (Sol et al. 2005; Lefebvre and Sol 2008; Overington et al. 2009; Sayol et al. 2016) and mammals (Deaner et al 2007; Sol et al. 2008; Reader et al. 2011; Benson et al. 2016), and a similar pattern can be inferred for 
amphibians and reptiles, in that large-brained species are more likely to thrive in a novel

environment than those with a relatively small brain (Amiel et al. 2011). Based on these findings, we explicitly assumed that, like in other, better-studied vertebrate taxa, variation in relative brain size captures variation in some important cognitive abilities across anurans.

Here, we examined the relationship between the relative size of the male brain, or of its major regions, and the operational sex ratio (OSR), breeding-population density and forelimb muscle mass as different indices of premating sexual selection across 30 species of anurans. Whereas the OSR is thought to be associated with the overall intensity of intrasexual selection (Emlen and Oring 1977), the spawning-population density and forelimb muscle mass might additionally inform about the relative importance of dyadic contests and the ability of males to monopolize females. Forelimb muscles are used in both dyadic contests and amplexus, and their relative mass varies with the relative importance of contest competition in intrasexual selection (Buzatto et al. 2015; Lüpold et al. 2017). In 10 of our species, we further explored the effect of these same breeding parameters on the brain size dimorphism between the sexes. If a larger brain is indicative of better cognitive abilities and these facilities indeed aid mate choice, scramble competition or male-male contests, we predict these proxies of mate competition to co-vary positively with relative brain size and that males should show a stronger response than females. 


\section{Materials and methods}

\section{Data collection}

For each of 30 anuran species, we measured the snout-vent length (SVL) as an index of body size and extracted the brains of $N=2$ to 20 males (mean $\pm \mathrm{SD}=5.6 \pm 4.1$ brains per species) that had been collected during the breeding season as part of previous studies (Wu et al. 2016; Zeng et al. 2016; Liao et al. 2016; table A1). For 10 of these species we further had samples for $20.9 \pm 7.1$ females (range 7 to 28 per species), which allowed us to examine sexual dimorphism in relative brain size (see Data analyses). All individuals per species originated from a single population or breeding pond.

In addition to the total brain volume, we also measured the volume of the main brain regions, including olfactory nerves, olfactory bulbs, telencephalon, optic tectum, cerebellum and ventral brain area (for details see fig. A1 and table A1). We chose these brain regions for consistency with previous comparative studies of anurans, in which they separately covaried with mate acquisition (Zeng et al. 2016) or environmental variables (Liao et al. 2015; Luo et al. 2017) that might also affect the intensity of male-male competition for mates.

To estimate the degree of species-specific male-male competition we determined the density and operational sex ratio (OSR) of the breeding populations for each of four ponds per species during the breeding season (April to June) between 2008 and 2017. In brief, during three consecutive nights, we searched for all mature individuals present at a given breeding pond using a 12-V flashlight, then captured, counted and sexed them based on their secondary sexual characteristics (i.e. nuptial pad in males and eggs readily visible through the skin of the 
abdomen in adult females). During the first night, we additionally leg-marked all individuals with a red string, during the second with a yellow string. During the third night, we only counted individuals by sex without marking. We calculated the species-specific OSR (expressed as the proportion of males among all adult individuals) for every breeding pond as the number of males divided by the number of females, averaged over three nights (see details in Mai et al. 2017). To determine pond sizes for calculations of population density, we measured the greatest length and width to calculate the surface area as $\mathrm{A}=$ length $\times$ width as most focal ponds were approximately rectangular. The spawning-site group size was the number of individuals per pond, from which we calculated the spawning-site density as the ratio between individuals present and the pond surface area. In addition, we calculated the spawning-site male density. For every species we determined the mean spawning-site group size, spawning-site (male or total) density and OSR across all four ponds. Although males of some anuran species have been reported to gain fertilizations by 'clutch piracy' without amplexus (Vieites et al. 2004), to the best of our knowledge this is not the case for any of our study species.

As an additional index of male-male competition, we included previously published data on male forelimb muscle mass (Lüpold et al. 2017). Males use their forelimbs in contests over territories or mates as well as to clasp the female during amplexus, particularly in cases where rival males attempt to dislodge them to take over the female (Buzatto et al. 2015; Lüpold et al. 2017). These forelimb muscles are prominent where males can monopolize mates, but relatively small where multi-male amplexus is difficult to avoid and investing in sperm production confers 
higher marginal fitness benefits (e.g., high population density; Buzatto et al. 2015; Lüpold et al. 2017).

\section{Phylogeny}

With a full coverage of 30 species, we reconstructed a molecular phylogeny based on a matrix of three nuclear and three mitochondrial genes to account for effects of common ancestry. The activating gene 1 (RAG1), rhodopsin (RHOD), and tyrosinase (TYR) were included in the nuclear genes. The mitochondrial genes of the recombination consisted of the cytochrome $b$ (CYTB), and the large and small subunits of the mitochondrial ribosome genes (12S/16S; the adjacent tRNAs was omitted as they were difficult to align and represented only a small amount of data). The GenBank accession numbers are shown in table A1. We aligned the sequences through the MUSCLE function in MEGA v.6.0.6 (Tamura et al. 2013) and used the Akaike Information Criterion in jModelTest v.2.1.7 (Darriba et al. 2012) to determine for each gene the best nucleotide substitution model. The best substitution model was GTR $+\Gamma+\mathrm{I}$ for both ribosomal genes and TYR, GTR $+\Gamma$ for RAG1 and $\mathrm{HKY}+\Gamma+\mathrm{I}$ for CYTB and RHOD, respectively.

Using these models, we constructed phylogenies (fig. A2) by using BEAUTi and BEAST v.1.8.3 (Drummond et al. 2012) with unlinked substitution models, a relaxed uncorrelated lognormal clock, a Yule speciation process, and no calibration points due to a lack of fossil dates. The Markov Chain Monte Carlo (MCMC) simulation was made to run for 100 million generations and we sampled a tree every $5000^{\text {th }}$ generation. The effective sample size (ESS) 
indicated satisfying convergence of the Bayesian chain and adequate model mixing for each of the tree statistics in the program Tracer v.1.6.0 (Rambaut et al. 2014). We generated a maximum clade credibility tree with mean node heights and a 10\% burn-in usingTreeAnnotatorv.1.8.3

(Drummond et al. 2012).

\section{Data analyses}

Throughout our analyses, we log-transformed all continuous variables except for the OSR, which was normally distributed without transformation. We first analyzed the interrelationships between our indices of male-male competition (i.e., spawning-site density, total group size, OSR and forelimb muscle mass) and body size, followed by their associations with size-corrected brain volume and the relative sizes of different brain compartments.

To distinguish between the effects of sexual and other forms of selection, we further tested the hypothesis that if male-male competition explains variation in relative brain size, then relative brain size should increase faster in males than in females as male-male competition intensifies. We therefore calculated an index of sexual dimorphism in relative brain size as the male: female ratio of the sex-specific brain size/SVL divisions sensu Bonduriansky and Rowe (2005): (brain size male $\left./ \mathrm{SVL}_{\text {male }}\right) /\left(\right.$ brain size $e_{\text {female }} / \mathrm{SVL}_{\text {female }}$ ). On a logarithmic scale, this index is > 0 when males have relatively larger brains than females, and $<0$ when females have relatively larger brains.

We conducted all statistical analyses in the R statistical environment version 3.6 ( $R$ Development Core Team 2019). We accounted for non-independence of data through shared 
ancestry using phylogenetic generalized least-squares (PGLS) models (Freckleton et al. 2002), based on the phylogeny above. To account for varying sample sizes between species that may affect the accuracy of species means, we performed our PGLS analyses in the R package nlme (Pinheiro et al. 2019), incorporating Pagel's (1999a) phylogenetic correlation structure (corPagel) as implemented in the ape package (Paradis et al. 2004) and weighting the model by the number of individuals measured. For analyses on sex differences, where different numbers of males and females were included, these weights were combined using the varComb function. These PGLS models estimate the phylogenetic scaling parameter $\lambda$ using maximum likelihood (Lynch 1991; Pagel 1999b). To evaluate the phylogenetic effect, we compared, using likelihood ratio tests, our model with estimated $\lambda$ to models with $\lambda$ set to 0 (phylogenetic independence) or 1 (complete phylogenetic dependence), respectively (Freckleton et al. 2002).

To avoid collinearity problems between forelimb muscle mass and body size when examining the body-size-corrected effect of forelimb muscle mass on brain size, we performed a sequential regression (Graham 2003; Lüpold 2013), with forelimb muscle mass entered as the original variable and SVL as the residuals from a regression on brain size (i.e., after removing the variation of forelimb muscle mass), which differs from the criticized use of residuals of the focal predictor (Freckleton 2002). In this sequential regression, forelimb muscle mass as the focal predictor is not to be interpreted as a direct effect but rather as its effect beyond its contribution through its relationship with body size, whereas information on body size itself is lost (Dormann et al. 2013). 
The functional neuroanatomy in anurans is still poorly understood on the gross-brain anatomical scale we were using. We were primarily interested in the relationships of the relative size of major brain regions with the spawning-population density and OSR, while abstaining from formulating additional predictions. Hence, we analyzed these relationships in separate PGLS models for every region, with the volume of the focal brain region as the response variable, and spawning-site density, OSR and total brain volume as predictor variables, weighted by sample size. The ventral brain volume was calculated as the difference between the total brain volume and the sum of all five measured brain regions.

\section{Results}

\section{Characteristics of the breeding populations}

The species-specific spawning-site density ranged between 0.65 and 3.20 individuals $/ \mathrm{m}^{2}$ across our sample of 30 anuran species, with a mean \pm SD of $1.94 \pm 0.73$ individuals $/ \mathrm{m}^{2}$. These density estimates were repeatable among the four sites per species $[R=0.67(95 \% \mathrm{CI}=0.49-0.79)$; fig. A3]. The operational sex ratio (OSR), measured as the proportion of males, ranged between 0.50 and 0.71 (mean $\pm \mathrm{SD}$ of $0.59 \pm 0.05$ ), with an intraspecific repeatability of $R=0.57(0.36-0.71$; fig. A3).In PGLS analyses, the OSR increased with the spawning-site density $(N=30, r=0.66$ $\left.(0.40-0.79), t=4.65, P=0.0001, \lambda<0.001^{1.00,<0.001}\right)$ but not with the total group size at the spawning site $\left(N=30, r=0.21(-0.16\right.$ to 0.51$\left.), t=1.14, P=0.27, \lambda<0.001^{1.00,<0.001}\right)$. Further, PGLS analyses on species-specific mean values $(N=30)$ weighted by sample size revealed no association of male body size with the spawning-site density $(r=-0.03$ ( -0.36 to 0.33$), t=-0.11$, 
$P=0.91, \lambda=0.90^{0.19,0.15}$ ), but weak positive trends with the total group size of the breeding population $\left(r=0.36(0.001-0.61), t=2.06, P=0.05, \lambda<0.001^{1.00,0.04}\right)$ and the OSR $(r=0.32$ $(-0.05$ to 0.58$\left.), t=1.79, P=0.08, \lambda=0.6^{0.05,0.55}\right)$.

\section{Male brain size}

In a PGLS controlling for body size $(N=30, r=0.92(0.84-0.95), t=11.73, P<0.0001)$ and weighted by sample size, male total brain size increased with both the OSR $\left(r=0.52\left(0.18^{-0.71)}\right.\right.$, $t=3.11, P=0.005$; fig. 1A $)$ and spawning-site density $(r=0.59(0.28-0.75), t=3.69, P=0.001$, $\lambda=0.32^{0.72,0.01}$; fig. 1B). Despite the correlations between the two population variables (see above), there was no severe collinearity between predictors (all variance inflation factors, VIF < 1.57).Total group size instead of spawning-site density had no significant effect $(N=30, r=0.30$ $(-0.08$ to 0.58$), t=1.60, P=0.12$; all other effects: $r>0.68, t>4.76, P \leq 0.0001, \lambda=0.14^{0.81,0.01}$, VIF < 1.16). Finally, as an additional estimate of male-male competition we used the sizecorrected mass of the males' forelimb muscles, which are under sexual selection though both amplexus and male-male wrestling matches and thus tend to be exaggerated in species with high levels of male-male competition (Lüpold et al. 2017). In a phylogenetically-informed sequential regression analysis to minimize multicollinearity (see Data analyses), forelimb muscle mass had a significant positive effect on relative brain size in males $(N=30, r=0.83(0.68-0.90), t=7.70$, $P<0.0001$; fig. 1C) in addition to its contribution through the residual body size as a covariate ( $r$ $=0.57(-0.27$ to 0.75$\left.), t=3.65, P=0.001, \lambda=0.59^{0.05,0.002} ; \mathrm{VIF}=1.00\right)$. 


\section{Sexual brain-size dimorphism}

A response of male brain size to proxies of male-male competition is no unambiguous evidence that sexual selection is indeed a key driver of male brain evolution. More direct evidence would be provided by a stronger response in males than in females (i.e., increasingly male-biased brain size dimorphism as male-male competition intensifies). We were able to test this prediction, albeit in only 10 of our 30 focal species for which females were available to measure brain size and compare brain size dimorphism relative to spawning-size density, OSR, total group size or male forelimb muscle mass. In PGLS analyses controlling for male and female sample sizes, amore male-biased OSR also enhanced the sexual dimorphism in relative brain size $(N=10, r=$ $0.96(0.85-0.98), t=9.55, P<0.0001, \lambda=1.00^{0.005,1.00}$; fig. $\left.2 \mathrm{~A}\right)$, whereas the site-specific breeding density was not associated in a separate analysis $(N=10, r=0.26$ ( -0.40 to 0.70$), t=$ $0.77, P=0.46, \lambda<0.001^{1.00,0.09} ;$ fig. $\left.2 \mathrm{~B}\right)$. Further, in a sequential regression analysis, male forelimb muscle mass also had a significant positive effect on the sexual dimorphism in relative brain size $(r=0.78(0.24-0.91), t=3.34, P=0.01)$ in addition to its non-significant contribution through residual body size $\left(r=0.12(-0.53\right.$ to 0.65$), t=0.31, P=0.77, \lambda=1.00^{0.02,1.00}$, VIF $=$ 3.94).

\section{Brain regions}

In the analyses of population structure on the relative size of different brain regions, the OSR had a negative effect on the relative volume of the olfactory nerves $(N=30, r=-0.58(-0.75$ to $\left.-0.27), t=-3.66, P=0.001, \lambda<0.0001^{1.0,<0.001}\right)$ and a similar tendency for the olfactory $\operatorname{bulb}(N=$ 
$30, r=-0.35(-0.61$ to 0.03$), t=-1.88, P=0.07, \lambda=0.21^{0.17,<0.001}$; table A2). All other brain regions were not affected by the OSR or spawning-site density (table A2).

\section{Discussion}

Our study of anuran brain evolution in the context of male competition over mates revealed that males of denser and more male-biased spawning aggregations exhibit relatively larger brains.

Similarly, the brain size of males covaried positively with the mass of their forelimb muscles as proxies of the relative importance of contest competition (Buzatto et al. 2015; Lüpold et al. 2017). Investing in costly weaponry thus does not seem to impede the evolution of larger brains despite causing an evolutionary trade-off with testes size (Lüpold et al. 2017). Importantly, the response of brain size to these indices of male-male competition was stronger in males than in females. These findings suggest that evolving a larger brain is beneficial when males compete for access to females. Below we argue that our results suggest a prominent role of cognitive abilities during male mate competition.

For our argument of a link between cognitive abilities and male mate competition, we explicitly assume that relatively larger brains are associated with greater cognitive abilities. While this has not been directly demonstrated in anurans, it may be inferred from the fact that such an association has been shown in most other vertebrate taxa using both comparative (MacLean et al. 2014; Benson-Amram et al. 2016) and artificial selection approaches (Roderick et al. 1973; Kotrschal et al. 2013; Buechel et al. 2018), and that larger-brained anurans live 
longer in the wild (Yu et al. 2018) and are better at adapting to novel environments (Amiel et al. 2011).

We found that both spawning-group density and the OSR were positively associated with male relative brain size. As density increases, males will encounter comparatively more other males, thus enhancing the intensity of competition for mating opportunities (Kokko and Rankin 2006). Importantly, we also found that denser groups showed more male-biased OSRs, which indicates that the highest levels of male mate competition occur in species with the densest mating groups. These were also the species with the largest male brain sizes. That relative brain size further increased with the relative forelimb muscle mass suggests that the relative importance of contest competition and female monopolization might indeed contribute to the anuran brain evolution. It only remains unclear whether there is a direct functional link between these two traits (e.g., larger brains being needed to control larger muscles) or whether male-male competition selects on relative brain size and forelimb muscles separately (i.e., cognition and strength, respectively) or even through an unmeasured mediator during development.

If we accept that a relatively larger brain provides better cognitive abilities also in anurans, those better cognitive abilities may confer several advantages during male mate competition. Theoretical models of animal contests (Enquist et al. 1983; Payne et al. 1996) and recent experimental evidence in brain-size selected guppies (van der Bijl et al. 2018) suggest that a larger brain allows for faster assessment of the outcome of a contest. Large-brained anurans may hence indirectly benefit during contests over females by conceding earlier when winning seems improbable, thereby saving energy for subsequent contests and/or minimizing potential damage. 
Direct benefits may include better positioning within spawning groups, or more flexible behavioral strategies depending on the physical strengths and/or competitive strategies of nearby males. Future experiments testing the role of brain size and cognitive abilities in mate competition will need to combine laboratory-based cognitive tests of males with subsequent behavioral observations of those males in competitive spawning situations.

We also investigated the relationships between the size of several important brain regions and indicators of male mate competition. As specific brain regions orchestrate different aspects of cognition (Nieuwenhuys et al. 1998), differences in their relative size could indicate which aspects of cognition are under particularly strong selection in anurans through male mate competition. We found a negative effect of OSR on the relative size of the olfactory nerves and such a trend for olfactory bulbs, but no further links between brain regions and indices of male competition. The two responding brain regions were also the only ones tending to respond to differences in the mating system or mode of mate acquisition in a previous study (Zeng et al. 2016).Specifically, Zeng et al. (2016) reported that these regions were more pronounced in species with single-compared to multi-male amplexus and that at least the olfactory bulb was relatively larger where males attract females with calls rather than actively searching for them. Since single-male amplexus and acoustic attraction of females by (territorial) males are both more likely to occur under less crowded and male-biased conditions, our results largely corroborate Zeng et al.'s (2016) findings. Although it is too early to draw more general conclusions on the involvement of olfaction in male mate competition, at least males of the mountain chicken frog, Leptodactylus fallax, have been shown to secrete a peptide from their 
skin that stimulates aggression in rivals, escalating in physical combat, but has no effect on females (King et al. 2005). It is thus possible that chemical communication also contributes to male-male contests in other taxa, including those studied here, and we encourage future exploration of such links using appropriate experimental work.

The 'social brain hypothesis' (SBH) prominently links social group size and brain size in vertebrates (Dunbar 1998) and suggests that a larger brain is beneficial for keeping track of intricate social interactions with a larger number of group members (Fischer et al. 2015; Farris et al. 2016; Roberts and Roberts 2016; Whiten and van de Waal 2017; Fox et al. 2017). However, apart from some studies in primates (Dunbar 1992; Barton 1996) and ungulates (Shultz and Dunbar 2006), social group size does not seem to be generally associated with brain evolution (Emery et al. 2007; Shultz and Dunbar 2007; West 2014). At face value, our frog results lend no support to the SBH as spawning group size was not associated with relatively larger brains. However, if males are largely confined to their territories and thus social interactions are limited nearby individuals, then a higher population density could increase the number of individuals that each male interacts with on a local scale, thus providing some support for the SBH.

Could predation pressure mediate the evolution of brain size in spawning aggregations of anurans? Protection from predation via 'selfish herd' or other group benefits (Hamilton 1971) often explain why animals aggregate, and predation pressure can select for variation in brain anatomy (Møller and Erritzøe 2014; Kotrschal et al. 2015; Kotrschal et al. 2017). Denser groups may be indicative of higher predation pressure, which has been linked to relatively larger brain size (Kondoh 2010; Kotrschal et al. 2017). Sex-specific predation on females during spawning 
may then lead to male-biased sex ratios in denser aggregations and be an alternative explanation for our main results. Data on predation rates for most of the species used here are not available and our data do not allow us to rule out this scenario, but we think it is unlikely. For one, studies reporting sex-specific survival rates for anurans in the wild typically find that males are predated on more heavily than females (Wood et al. 1998), possibly due to their higher conspicuousness through courtship displays or mating calls. Also, for the one species of this study for which field predation rates are known, the Omei wood frog (Rhacophorus omeimontis), males and females fall to predation at similar rates (Liao 2009).

Finally, it is important to understand whether the OSR and spawning-site density are simply a consequence of variation in the life history (e.g. longevity, age at sexual maturity) or seasonality, which have previously been shown to explain variation in relative male brain size in anurans (Luo et al. 2017; Yu et al. 2018), with the life-history variables also driving spawning-site density (Cai et al. 2019). Combined examination (appendix C) indicated that neither the lifehistory nor the seasonality variables had a direct effect on relative brain size. Rather they were mediated by the density and/or OSR of the spawning aggregations. Hence, even if life history and breeding ecology have separately been found to influence the evolution of male brain size, this might be because they shape the density and structure of spawning aggregations. These population parameters, associated with the competition among males, might then be the primary drivers of anuran brain evolution. However, before we can draw any final conclusions on these patterns, we need larger datasets to more robustly disentangle these dependencies jointly. 
To conclude, we found that frog species that spawn in more male-biased and denser spawning groups have relatively larger brains and interpret this as evidence for cognitive adaptations to more intense male-male competition over mates. This interpretation is further supported by the stronger response of male compared to female brain size to these proxies of premating, intrasexual selection. Our results expand the taxonomic breadth of studies on the role of sexual selection in brain evolution and highlight a potentially new avenue of research with the possibility that chemical communication could play an underappreciated role in male contests over mates. Thorough experimental exploration of the links between anuran cognition and brain anatomy are now needed for a more comprehensive understanding of anuran brain evolution and its social drivers.

\section{Online data deposition}

All data are deposited on Dryad Digital Repository, doi:10.5061/dryad.95x69p8g5 (Mai et al. 2020).

\section{Acknowledgements}

We thank Long Jin, Shang Ling Lou and Cheng Chen for help in the field. Financial support was provided by the National Natural Sciences Foundation of China (31970393 and 31772451 to LWB), Key Cultivation Foundation of China West Normal University (17A006to LWB), Talent Project of China West Normal University (17YC335to LWB), the Swiss National Science Foundation (PP00P3_170669 to SL), and the Swedish Research Council (2017-04957 to AK). 
The reported experiments comply with the current laws of China concerning animal experimentation, and permit to collect amphibians from the Ethical Committee for Animal Experiments in China Council on Animal Care (CCAC) was in hand at the time of sampling.

\section{Author contributions}

CLM and WBL conceived the study and collected the data; CLM, WBL and SL analyzed data and wrote methods and results; SL and AK prepared the figures and wrote the rest of the manuscript. All authors gave final approval for publication. 


\section{Appendix A: Phylogenetic details, measurements, and supplementary analyses}

Table A1: Genbank accession numbers for the gene sequences used to generate the phylogeny.

\begin{tabular}{|c|c|c|c|c|c|c|}
\hline Species & $12 S$ & $16 \mathrm{~S}$ & CYTB & RAG1 & RHOD & TYR \\
\hline Amolops lifanensis & DQ359981.1 & DQ204482.1 & KJ008458.1 & & DQ360034.1 & DQ360065.1 \\
\hline Amolops mantzorum & DQ359970.1 & & KJ008405.1 & EF088240.1 & DQ360023.1 & DQ360054.1 \\
\hline Bufo andrewsi & AF160764.1 & AF160782.1 & & DQ158353.1 & DQ283905.1 & \\
\hline Bufo gargarizans & NC_008410.1 & NC_008410.1 & JN647482.1 & KF666177.1 & & \\
\hline Bufo minshanicus & KM587710.1 & KM587710.1 & & & & \\
\hline Feirana quadranus & GQ225906.1 & GQ225932.1 & KX021999.1 & HM163591.1 & EU979886.1 & EU979981.1 \\
\hline Fejervarya multistriata & & AF206466.1 & АB296096.1 & AB526660.1 & DQ458271.1 & EU980027.1 \\
\hline Hyla annectansc huanxiensis & KP742566.1 & & FJ226919.1 & & & \\
\hline Hyla annectans jingdongensis & KP742564.1 & & AY843821.1 & & AY844574.1 & AY844045.1 \\
\hline Hyla tsinlingensis & KP742646.1 & KP212702.1 & JX870448.1 & & & \\
\hline Hylarana guentheri & & KF185060.1 & KR264131.1 & KR264365.1 & DQ284009.1 & KR264440.1 \\
\hline Kaloula rugifera & JX678894.1 & JX678911.1 & KT878719.1 & & & \\
\hline Kaloula verrucosa & KC822507.1 & KC822507.1 & & & & \\
\hline Microhyla ornata & АВ201177.1 & DQ512876.1 & AB201223.1 & AY364198.1 & AY364383.1 & KC180221.1 \\
\hline Nanorana parkeri & & DQ118498.1 & KJ434188.1 & HM163584.1 & EU979872.1 & DQ458276.1 \\
\hline Odorrana grahami & EF453731.1 & EU861555.1 & & EF088257.1 & DQ360016.1 & DQ360047.1 \\
\hline Odorrana margaretae & DQ359964.1 & EU861566.1 & KJ815050.1 & EF088261.1 & DQ360017.1 & DQ360048.1 \\
\hline Paa boulengeri & EU979791.1 & EU979851.1 & JX676597.1 & HM163604.1 & EU979918.1 & EU980033.1 \\
\hline Paa yunnanensis & GQ225869.1 & GQ225873.1 & KF199150.1 & HM163593.1 & DQ458263.1 & EU979976.1 \\
\hline Pelophyla xhubeiensis & AF205547.1 & AF315137.1 & & & & \\
\hline Pelophylax nigromaculata & DQ359961.1 & JQ621942.1 & DQ006266.1 & AB360184.1 & DQ283838.1 & DQ360045.1 \\
\hline Pelophylax pleuraden & JN541324.1 & JQ621943.1 & KR264150.1 & KR264384.1 & DQ360011.1 & DQ360042.1 \\
\hline Polypedates megacephalus & KU840483.1 & AY880519.1 & $\mathrm{AB} 451722.1$ & EU924517.1 & EU924545.1 & KC180271.1 \\
\hline Rana chensinensis & DQ289095.1 & DQ289121.1 & KM211950.1 & KX269551.1 & & KX269779.1 \\
\hline Rana kukunoris & KX269185.1 & KX269185.1 & JX486345.1 & GQ285780.1 & GQ285798.1 & GQ285816.1 \\
\hline Rana omeimontis & KX269193.1 & DQ289108.1 & AF274928.1 & KX269558.1 & & KX269785.1 \\
\hline Rhacophorus chenfui & GQ204763.1 & KU840563.1 & EU924603.1 & EU924519.1 & EU924547.1 & KU840751.1 \\
\hline Rhacophorus dennysi & DQ019592.1 & DQ019609.1 & EU924604.1 & DQ019512.1 & EU215575.1 & EU924576.1 \\
\hline Rhacophorus dugritei & EF564471.1 & EF564541.1 & EU924605.1 & GQ285768.1 & EU215571.1 & EU215601.1 \\
\hline Rhacophorus omeimontis & KU840492.1 & KU840564.1 & EU924612.1 & EU924528.1 & EU215565.1 & KU840753.1 \\
\hline
\end{tabular}


Table A2: Results of phylogenetic generalized least-squares regressions examining the effects of breeding-site density and OSR on the relative size of brain regions. All analyses are weighted by sample size. Values of the phylogenetic scaling factor $\lambda$ are followed the $P$-values of likelihood ratio tests against models with $\lambda$ set to 0 or 1 , respectively.

\begin{tabular}{|c|c|c|c|c|c|c|}
\hline Responses & Predictors & $r$ & LCL, UCL & $t$ & $P$ & $\lambda$ \\
\hline \multirow[t]{3}{*}{ Olfactory nerves } & Brain size & -0.79 & $0.61,0.88$ & 6.63 & $<0.001$ & $<0.001^{1.00,<0.01}$ \\
\hline & $\begin{array}{l}\text { Spawning-site } \\
\text { density }\end{array}$ & -0.05 & $-0.40,0.31$ & -0.28 & 0.782 & \\
\hline & OSR & -0.58 & $-0.75,-0.27$ & -3.66 & 0.001 & \\
\hline \multirow[t]{3}{*}{ Olfactory bulb } & Brain size & 0.78 & $0.58,0.87$ & 6.27 & $<0.001$ & $0.21^{0.17,<0.001}$ \\
\hline & $\begin{array}{l}\text { Spawning-site } \\
\text { density }\end{array}$ & -0.05 & $-0.40,0.31$ & -0.27 & 0.786 & \\
\hline & OSR & -0.35 & $-0.61,0.03$ & -1.88 & 0.071 & \\
\hline \multirow[t]{3}{*}{ Telencephalon } & Brain size & 0.74 & $0.51,0.85$ & 5.63 & $<0.001$ & $<0.001^{1,0.002}$ \\
\hline & $\begin{array}{l}\text { Spawning-site } \\
\text { density }\end{array}$ & -0.18 & $-0.52,0.20$ & -0.96 & 0.347 & \\
\hline & OSR & -0.26 & $-0.55,0.12$ & -1.40 & 0.174 & \\
\hline \multirow[t]{3}{*}{ Optic tectum } & Brain size & 0.83 & $0.69,0.90$ & 7.77 & $<0.001$ & $<0.001^{1.00,<0.001}$ \\
\hline & $\begin{array}{l}\text { Spawning-site } \\
\text { density }\end{array}$ & -0.23 & $-0.53,0.16$ & -1.18 & 0.248 & \\
\hline & OSR & -0.23 & $-0.53,0.15$ & -1.23 & 0.231 & \\
\hline \multirow[t]{3}{*}{ Cerebellum } & Brain size & 0.77 & $0.58,0.86$ & 6.20 & $<0.001$ & $<0.001^{1.00,<0.001}$ \\
\hline & $\begin{array}{l}\text { Spawning-site } \\
\text { density }\end{array}$ & 0.06 & $-0.31,0.40$ & 0.28 & 0.781 & \\
\hline & OSR & -0.12 & $-0.45,0.26$ & -0.59 & 0.557 & \\
\hline \multirow[t]{3}{*}{ Ventral brain area } & Brain size & 0.89 & $0.78,0.93$ & 9.77 & $<0.001$ & $<0.001^{1.00,<0.001}$ \\
\hline & $\begin{array}{l}\text { Spawning-site } \\
\text { density }\end{array}$ & 0.20 & $-0.19,0.51$ & 1.01 & 0.320 & \\
\hline & OSR & 0.27 & $-0.12,0.55$ & 1.40 & 0.172 & \\
\hline
\end{tabular}

[Figure A1 goes here]

[Figure A2 goes here]

[Figure A3 goes here] 


\section{Literature Cited}

Andersson, M. 1994. Sexual selection. Princeton University Press, Princeton, New Jersey.

Allman, J. 2000. Evolving brains. Scientific American Library, New York.

Amiel, J.J., R. Tingley, and R. Shine. 2011. Smart moves: Effects of relative brain size on establishment success of invasive amphibians and reptiles. PLoS One 6:e18277.

Barton, R.A. 1996. Neocortex and behavioural ecology in primates. Proceedings of the Royal Society B 263:173-177.

Benson-Amram, S., B. Dantzer, G. Stricker, E.M. Swanson, and K.E. Holekamp. 2016. Brain size predicts problem-solving ability in mammalian carnivores. Proceedings of the National Academy of Sciences of the USA 113:2532-2537.

Bonduriansky, R., and L. Rowe. 2005. Sexual selection, genetic architecture, and the condition dependence of body shape in the sexually dimorphic fly Prochyliza xanthostoma (Piophilidae). Evolution 59:138-151.

Boogert, N.J., T.W. Fawcett,and L. Lefebvre. 2011. Mate choice for cognitive traits: a review of the evidence in nonhuman vertebrates. Behavioral Ecology 22:447-459.

Buechel, S.D., A. Boussard, A. Kotrschal, W.V.D. Bijl, and N. Kolm. 2018. Brain size affects performance in a reversal-learning test. Proceedings of the Royal Society B 285:20172031.

Buzatto, B.A., J.D. Roberts, and L.W. Simmons. 2015. Sperm competition and the evolution of precopulatory weapons: Increasing male density promotes sperm competition and reduces selection on arm strength in a chorusing frog. Evolution 69:2613-2624.

Cai, Y.L., C.L. Mai, and W.B. Liao. 2019. Frogs with denser group-spawning mature later and live longer. Scientific Reports 9:13776.

Chen, J.N., Y.Q. Zou, Y.H. Sun, and C. ten Cate. 2019. Problem-solving males become more attractive to female budgerigars. Science 363:166-167. 
Corral-López, A., N. Bloch, A. Kotrschal, W. van der Bijl, S. Buechel, J.E. Mank, et al. 2017. Female brain size affects the assessment of male attractiveness during mate choice. Science Advances 3:e1601990.

Corral-López, A., A. Kotrschal, and N. Kolm. 2018. Selection for relative brain size affects context-dependent male preferences, but not discrimination, of female body size in guppies. Journal of Experimental Biology 221:jeb175240.

Darriba, D., G.L. Taboada, R. Doallo, and D. Posada. 2012. jModelTest 2: more models, new heuristics and parallel computing. Nature Methods 9:772.

Deaner, R.O., K. Isler, J. Burkart and C.P. van Schaik. 2007. Overall brain size and not encephalization quotient, best predicts cognitive ability across non-human primates. Brain, Behavior and Evolution 70:115-124.

Dormann, C.F., J. Elith, S. Bacher, C. Buchmann, G. Carl, G. Carré, J.R. García Marquéz, B. Gruber, B. Lafourcade, P.J. Leitão, T. Münkemüller, C. McClean, P.E. Osborne, B. Reineking, B. Schröder, A.K. Skidmore, D. Zurell, and S. Lautenbach. 2013. Collinearity: a review of methods to deal with it and a simulation study evaluating their performance. Ecography 36:27-46.

Drummond, A.J., M.A. Suchard, D. Xie, and A. Rambaut. 2012. Bayesian phylogenetics with BEAUti and the BEAST 1.7. Molecular Biology and Evolution 2:1969-1973.

Dunbar, R.I.M. 1992. Neocortex size as a constraint on group size in primates. Journal of Human Evolution 20:469-493.

Dunbar, R.I.M. 1998. The social brain hypothesis. Evolutionary Anthropology 6:178-190.

Emery, N.J., A.M. Seed, A.M. von Bayern, and N.S. Clayton 2007. Cognitive adaptations of social bonding in birds. Philosophical Transactions of the Royal Society of London B 362: 489-505.

Emlen, D.J. 2008. The evolution of animal weapons. Annual Review of Ecology, Evolution, and Systematics 39:387-413.

Emlen, S.T., and L.W. Oring. 1977. Ecology, sexual selection, and the evolution of mating systems. Science197:215-223. 
Enquist, M., and O. Leimar. 1983. Evolution of fighting behaviour: Decision rules and assessment of relative strength. Journal of Theoretical Biology 102:387-410.

Farris, S.M. 2016. Insect societies and the social brain. Current Opinion in Insect Science 15:1-8.

Fischer, S., M. Bessert-Nettelbeck, A. Kotrschal, and B. Taborsky. 2015. Rearing-group size determines social competence and brain structure in a cooperatively breeding Cichlid. American Naturalist 186:123-140.

Fitzpatrick, J.L., M. Almbro, A. Gonzalez-Voyer, S. Hamada, C. Pennington, and J. Scanlan, and N. Kolm. 2012. Sexual selection uncouples the evolution of brain and body size in pinnipeds. Journal of Evolutionary Biology 25:1321-1330.

Fox, K.C.R., M. Muthukrishna, and S. Shultz. 2017. The social and cultural roots of whale and dolphin brains. Nature Ecology \& Evolution 1:1699-1705.

Freckleton, R.P. 2002. On the misuse of residuals in ecology: regression of residuals vs. multiple regression. Journal of Animal Ecology 71:542-545.

Freckleton, R.P., P.H. Harvey, and M. Pagel. 2002. Phylogenetic analysis and comparative data: a test and review of evidence. American Naturalist 160:712-726.

Garamszegi, L.Z., M. Eens, J. Erritzøe, and A.P. Møller. 2005. Sperm competition and sexually size dimorphic brains in birds. Proceedings of the Royal Society B 272:159-166.

García-Peña, G. E., D. Sol, A.N. Iwaniuk, and T. Székely. 2013. Sexual selection on brain size in shorebirds (Charadriiformes). Journal of Evolutionary Biology 26:878-888.

Gonzalez-Voyer, A., and N. Kolm. 2010. Sex, ecology and the brain: evolutionary correlates of brain structure volumes in Tanganyikan cichlids. PLoS One 5:e14355.

Graham, M.H. 2003. Confronting multicollinearity in ecological multiple regression. Ecology 84:2809-2815.

Hamilton, W.D.1971. Geometry for the selfish herd. Journal of Theoretical Biology 31:295-311. Jacobs, L.F. 1996. Sexual selection and the brain. Trends in Ecology and Evolution 11:A82-A86. 
King, J.D., L.A. Rollins-Smith, P.F. Nielsen, A. John, and J.M. Conlon. 2005. Characterization of a peptide from skin secretions of male specimens of the frog, Leptodactylus fallax that stimulates aggression in male frogs. Peptides 26:597-601.

Kokko, H., and D.J. Rankin. 2006. Lonely hearts or sex in the city? Density-dependent effects in mating systems. Philosophical Transactions of the Royal Society of London B 361:319334.

Kondoh, M. 2010. Linking learning adaptation to trophic interactions: a brain size-based approach. Functional Ecology 24:35-43.

Kotrschal, A., S. Buechel, S. Zala, A. Corral Lopez, D.J. Penn, and N. Kolm. 2015. Brain size affects female but not male survival under predation threat. Ecology Letters 18:646-652.

Kotrschal, A., A. Corral-Lopez, M. Amcoff and N. Kolm. 2014. A larger brain confers a benefit in a spatial mate search learning task in male guppies. Behavioral Ecology 26:527-532.

Kotrschal, A., A.E. Deacon, E.A. Magurran, and N. Kolm. 2017. Predation pressure shapes brain anatomy in the wild. Evolutionary Ecology 31:619-633.

Kotrschal, A., B. Rogell, A. Bundsen, B. Svensson, S. Zajitschek, I. Brännström, S. Immler, A. A. Maklakov, and N. Kolm. 2013. Artificial selection on relative brain size in the guppy reveals costs and benefits of evolving a larger brain. Current Biology 23:168-171.

Lemaitre, J.F., S.A. Ramm, R.A. Barton, and P. Stockley. 2009. Sperm competition and brain size evolution in mammals. Journal of Evolutionary Biology 22:2215-2221.

Lefebvre, L. and D. Sol. 2008. Brains, lifestyles and cognition: are there general trends? Brain, Behavior and Evolution 72:135-144.

Liao, W.B. 2009. Elevational variation in the life-history of anurans in a subtropics montane forest of Sichuan, southwestern China. PhD thesis. China: Wuhan University.

Liao, W.B., S.L. Lou, Y. Zeng, and A. Kotrschal. 2016. Large brains, small guts: The expensive tissue hypothesis supported in anurans. American Naturalist 188:693-700.

Liao, W.B., S.L. Lou, Y. Zeng, and J. Merilä. 2015. Evolution of anuran brains: disentangling ecological and phylogenetic sources of variation. Journal of Evolutionary Biology 28:1986-1996. 
Lindenfors, P., C.L. Nunn, and R.A. Barton. 2007. Primate brain architecture and selection in relation to sex. BMC Biol. 5: 20.

Luo, Y., M.J. Zhong, Y. Huang, F. Li, W.B. Liao, and A. Kotrschal. 2017. Seasonality and brain size are negatively associated in frogs: evidence for the expensive brain framework. Scientific Reports 7:16629.

Lüpold, S. 2013. Ejaculate quality and constraints in relation to sperm competition levels among eutherian mammals. Evolution 67:3052-3060.

Lüpold, S., L. Jin, and W.B. Liao. 2017. Population density and structure drive differential investment in pre- and postmating sexual traits in frogs. Evolution 71:1686-1699.

Lüpold, S., J.L. Tomkins, L.W. Simmons, and J.L. Fitzpatrick. 2014. Female monopolization mediates the relationship between pre- and postcopulatory sexual traits. Nature Communications 5:3184.

Lynch, M. 1991. Methods for the analysis of comparative data in evolutionary biology. Evolution 45:1065-1080.

Maclean, E. L., B. Hare, C. L. Nunn, E. Addessi,F. Amici, R.C. Anderson, et al. 2014. The evolution of self-control. Proceedings of the National Academy of Sciences of the USA 111:E2140-E2148.

Madden, J. 2001. Sex, bowers and brains. Proceedings of the Royal Society B 268:833-838.

Mai, C.L., J. Liao, L. Zhao, S.M. Liu, and W.B. Liao. 2017. Brain size evolution in the frog Fejervarya limnocharis does neither support the cognitive buffer nor the expensive brain framework hypothesis. Journal of Zoology 302:63-72.

Mai, C.L., and W.B. Liao. 2019. Brain size evolution in anurans: a review. Animal Biology69:265-279.

Mai, C. L., W. B. Liao, S. Lüpold, and A. Kotrschal. 2020. Data from: Relative brain size is predicted by the intensity of intrasexual competition in frogs. American Naturalist, Dryad Digital Repository, https://doi.org/10.5061/dryad.95x69p8g5.

Miller, G.F. 2000. The mating mind: How sexual selection shaped the evolution of human nature. William Hienemann, London. 
McCullough, E.L., B.A. Buzatto, and L.W. Simmons. 2018. Population density mediates the interaction between pre- and postmating sexual selection. Evolution 72:893-905.

McDonald, G.C., L.G. Spurgin, E.A. Fairfield, D.S. Richardson, and T. Pizzari. 2017. Pre- and postcopulatory sexual selection favor aggressive, young males in polyandrous groups of red junglefowl. Evolution 71:1653-1669.

Mink, J.W., R.J. Blumenschine, and D.B. Adams. 1981. Ratio of central nervous system to body metabolism in vertebrates: its constancy and functional basis. American Journal of Physiology 241:R203-R212.

Møller, A.P., and J. Erritzøe. 2014. Predator-prey interactions, flight initiation distance and brain size. Journal of Evolutionary Biology 27:34-42.

Nieuwenhuys, R., H.J. ten Donkelaar, and C. Nicholson. 1998. The central nervous system of vertebrates. Springer, Heidelberg.

Orme, C.D.L., R.P. Freckleton, G.H. Thomas,T. Petzoldt, and S.A.Fritz. 2012.caper:

Comparative analyses of phylogenetics and evolution in R. http://R-Forge.Rproject.org/projects/caper/.

Overington, S.E., J. Morand-Ferron, N.J. Boogert, and L. Lefebvre. 2009. Technical innovations drive the relationship between innovativeness and residual brain size in birds. Animal Behaviour 78:1001-1010.

Pagel, M. 1999. The maximum likelihood approach to reconstructing ancestral characterstates of discrete characters on phylogenies. Systematic Biology 48:612-622.

Pagel, M. 1999a. Inferring the historical patterns of biological evolution. Nature 401:877-884.

Paradis, E., J. Claude, and K. Strimmer. 2004. APE: Analyses of phylogenetics and evolution in R language. Bioinformatics 20:289-290.

Parker, G. A., C. M. Lessells, and L. W. Simmons. 2013. Sperm competition games: a general model for pre-copulatory male-male competition. Evolution 67:95-109.

Payne, R.J.H., and M. Pagel. 1996. Escalation and time costs in displays of endurance. Journal of Theoretical Biology 183:185-193. 
Pinheiro, J., D. Bates, S. DebRoy, and D. Sarkar. 2019. nlme: Linear and nonlinear mixed effects models. Available at: https://cran.r-project.org/package=nlme.

Pitnick, S., K. E. Jones, and G. S. Wilkinson. 2006. Mating system and brain size in bats. Proceedings of the Royal Society B 273:719-724.

R Development Core Team. 2019. A language and environment for statistical computing. Available at: http://www.R-project.org.

Rambaut, A., and A. Drummond. 2014. Tracer v1.6. Available at: http://tree.bio.ed.ac.uk/software/tracer/.

Reader, S.M., Y. Hager and K. N. Laland. 2011. The evolution of primate general and cultural intelligence. Philosophical Transactions of the Royal Society of London B366:10171027.

Roberts, S.G.B., and A.I. Roberts. 2016. Social brain hypothesis: Vocal and gesture networks of wild chimpanzees. Frontiers in Psychology 7:1756.

Roderick, T.H., R.E. Wimer, C.C. Wimer,and P.A.Schwartzin. 1973. Genetic and phenotypic variation in weight of brain and spinal-cord between inbred strains of mice. Brain Research 64:345-353.

Sayol, F., L. Lefebvre, and D. Sol. 2016. Relative brain size and its relation with the associative pallium in birds. Brain, Behavior and Evolution 87:69-77.

Schillaci, M.A. 2006. Sexual selection and the evolution of brain size in primates. PLoS One $1: \mathrm{e} 62$.

Shultz, S., and R.I.M. Dunbar. 2006. Both social and ecological factors predict ungulate brain size. Proceedings of the Royal Society B 273:207-215.

Shultz, S., and R.I.M. Dunbar. 2007. The evolution of the social brain: anthropoid primates contrast with other vertebrates. Proceedings of the Royal Society B 274:2429-2436.

Sol, D., S. Bacher, S.M. Reader and L. Lefebvre. 2008. Brain size predicts the success of mammal species introduced into novel environments. American Naturalist 172:S63-S71. 
Sol, D., L. Lefebvre and J. D. Rodriguez-Teijeiro. 2005. Brain size, innovative propensity and migratory behaviour in temperate Palaearctic birds. Proceedings of the Royal Society B 272:1433-1441.

Tamura, K., G. Stecher, D. Peterson, A. Filipski, and S. Kumar. 2013. MEGA6: Molecular evolutionary genetics analysis version 6.0. Molecular Biology and Evolution 30:27252729.

van der Bijl, W., S.D. Buechel, A. Kotrschal, and N. Kolm. 2018. Revisiting the social brain hypothesis: contest duration depends on loser's brain size. BioRxivhttps://doi.org/10.1101/300335.

Vieites,D. R., S. Nieto-Román, M. Barluenga, A. Palanca, M. Vences, and A. Meyer. 2004. Postmating clutch piracy in an amphibian. Nature 431:305-308.

Wells, K. 1977. The social behaviour of anuran amphibians. Animal Behaviour 25:666-693.

West, R.J.D. 2014. The evolution of large brain size in birds is related to social, not genetic, monogamy. Biological Journal of the Linnean Society 111:668-678.

Whiten, A., and E. van de Waal. 2017. Social learning, culture and the 'socio-cultural brain' of human and non-human primates. Neuroscience \& Biobehavioral Reviews. 82:58-75.

Wood, K.V., J.D.Nichols, H.F. Percival, and J.E.Hines. 1998. Size-sex variation in survival rates and abundance of pig frogs, Rana grylio, in northern Florida wetlands. Journal of Herpetology 32:527-535.

Wu, Q.G., S.L. Lou, Y. Zeng, and W.B. Liao. 2016. Spawning location is linked to the relative size of olfactory nerves in anurans. Herpetological Journal 26:245-248.

Yu, X., M.J. Zhong, D.Y. Li, L. Jin, W.B. Liao, and A. Kotrschal. 2018. Large-brained frogs mature later and live longer. Evolution 72:1174-1183.

Zeng, Y., S.L. Lou, W.B. Liao, R. Jehle, and A. Kotrschal. 2016. Sexual selection impacts brain anatomy in frogs and toads. Ecology \& Evolution 6:7070-7079. 


\section{References Cited Only in the Online Enhancements}

von Hardenberg, A., and A. Gonzalez-Voyer. 2013. Disentangling evolutionary cause-effect relationships with phylogenetic confirmatory path analysis. Evolution 67:378-387. 


\section{Figure legends}

Figure 1: Phylogenetically controlled relationships between relative male brain size and (A) the operational sex ratio $(r=0.52, P=0.005),(\mathrm{B})$, the spawning-site density $(r=0.59, P=$ $0.001)$, and $(\mathrm{C})$ the male forelimb muscle $\operatorname{mass}(r=0.83, P<0.0001)$ across the 30 anuran species studied. Panels A and B were derived from the same model, with both axes controlled for body size and the non-focal population variable. In panel C, both axes are controlled for residual body size in a sequential regression approach.

Figure 2: Relationships between sexual brain-size dimorphism and (A) the operational sex ratio $(r=0.96, P<0.001),(\mathrm{B}), \log$ spawning-site density $(r=0.26, P=0.46)$, and $(\mathrm{C})$ residual male forelimb muscle mass $(r=0.78, P=0.01)$ across 10 anuran species with brain size data for both sexes. Whereas bivariate models are represented in panels A and B, both axes are controlled for residual body size in panel $\mathrm{C}$, based on a sequential regression approach.

Figure A1: Dorsal, lateral and ventral views of a frog brain showing the different brain regions measured, including the olfactory nerves, olfactory bulbs, telencephalon, optic tectum, and cerebellum.

Figure A2: The phylogenetic tree of the 30 species of anurans in the comparative analysis. For the species highlighted in bold we also had data on female brain size that could be used for the analyses on sexual brain-size dimorphism. 
Figure A3: Boxplot reflecting the intraspecific repeatability in estimates of the spawningsite density (A) and operational sex ratio (B) across 4 sites per species, each based on counts on three consecutive nights per site. 


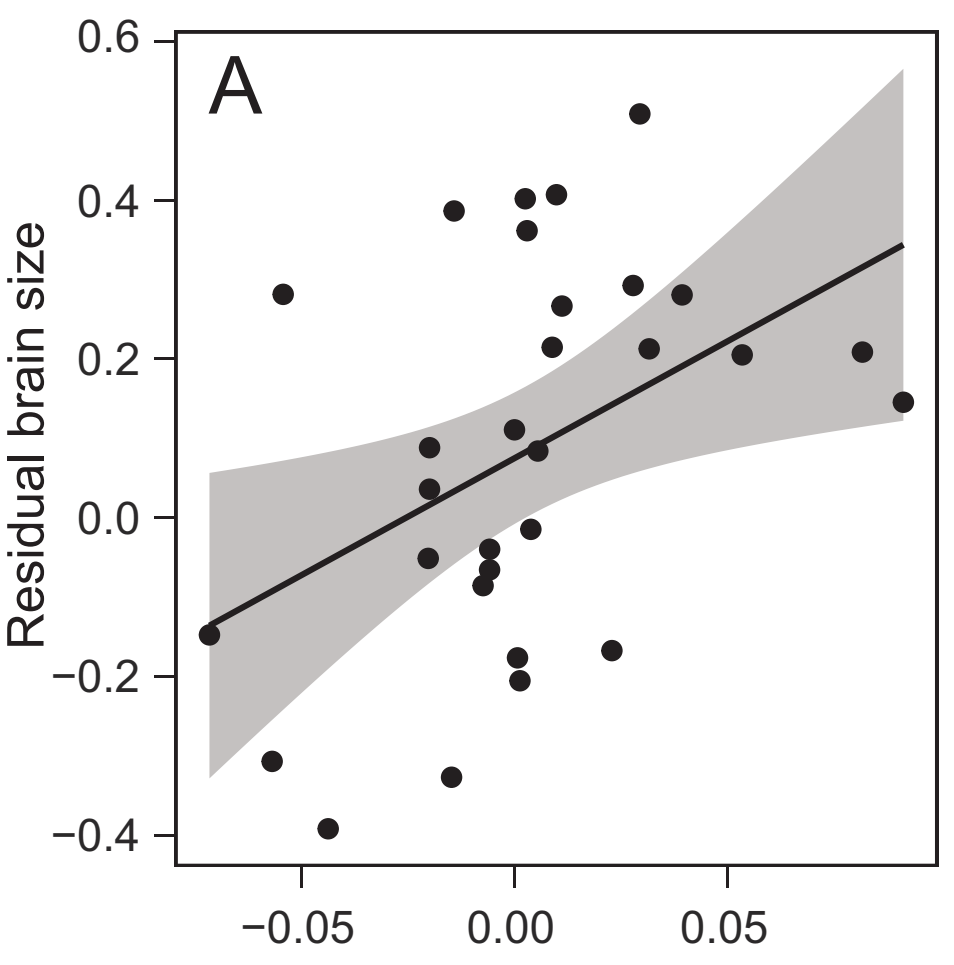

Residual operational sex ratio
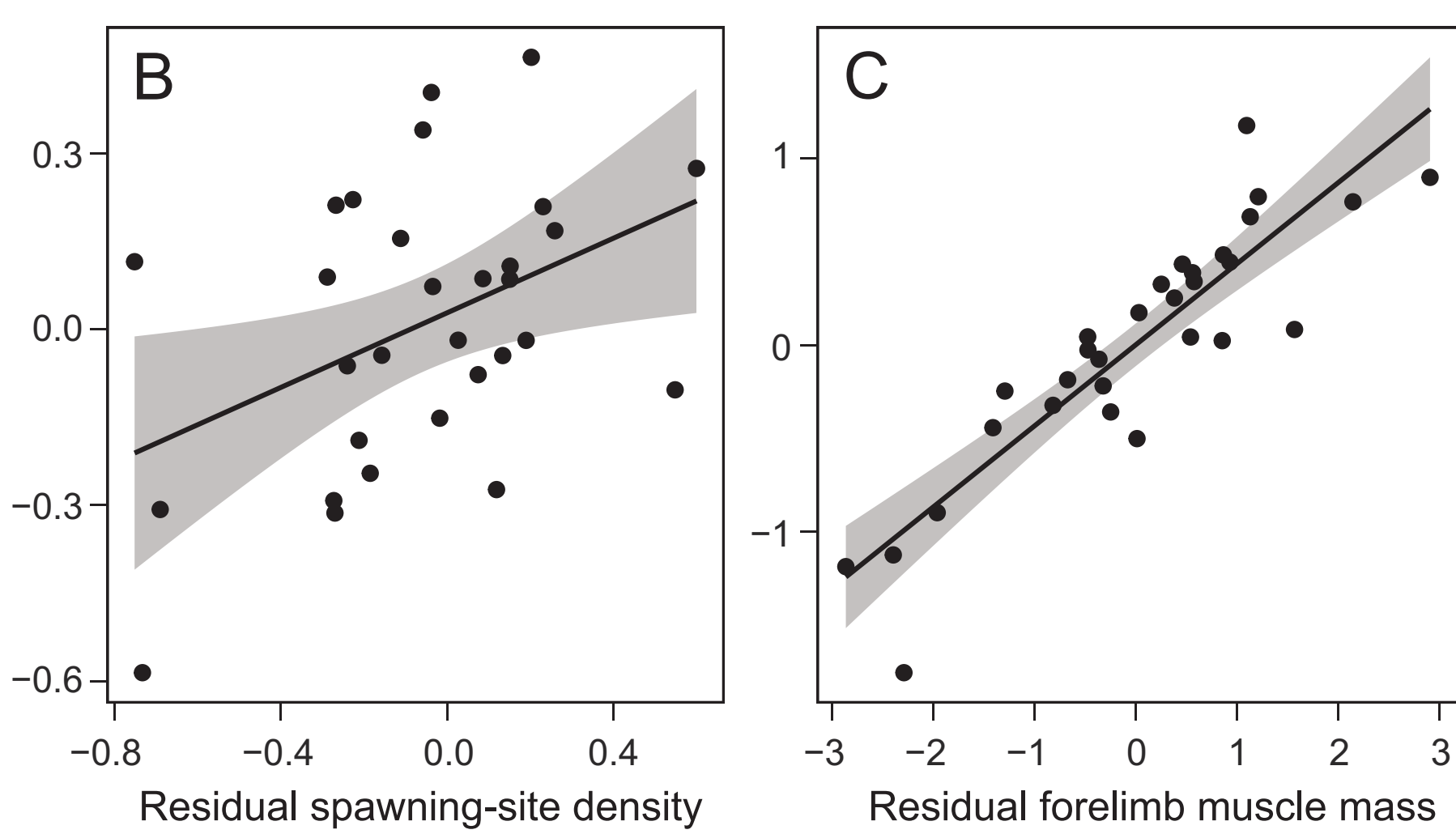

Residual forelimb muscle mass 

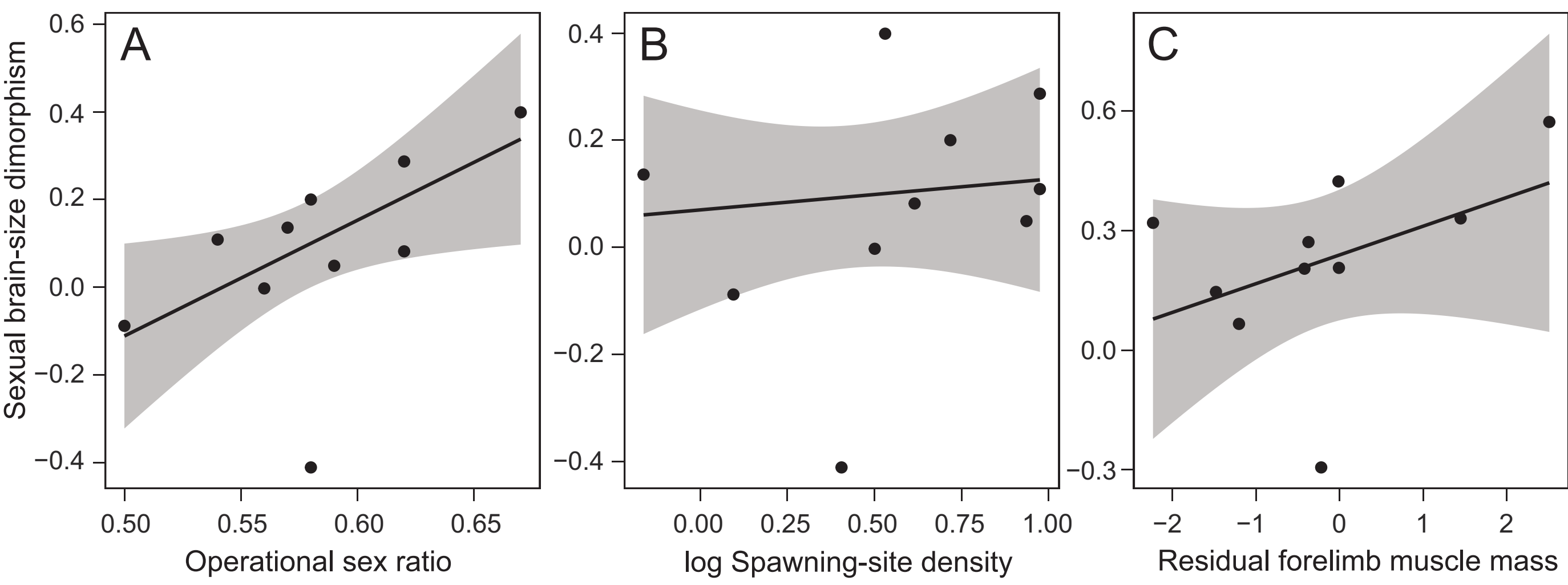


\section{Figure A1}
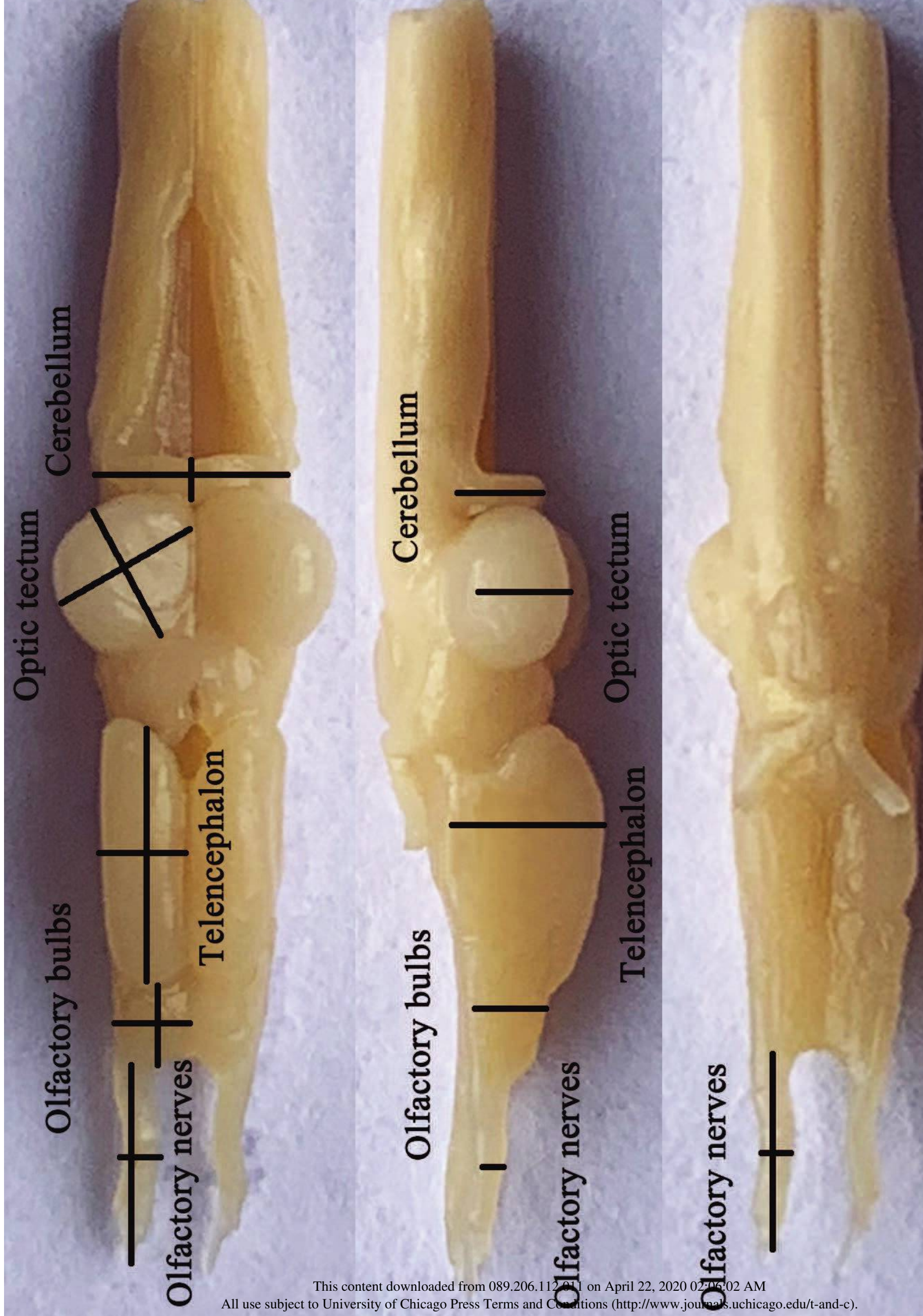

음

. 
Bufo gargarizans

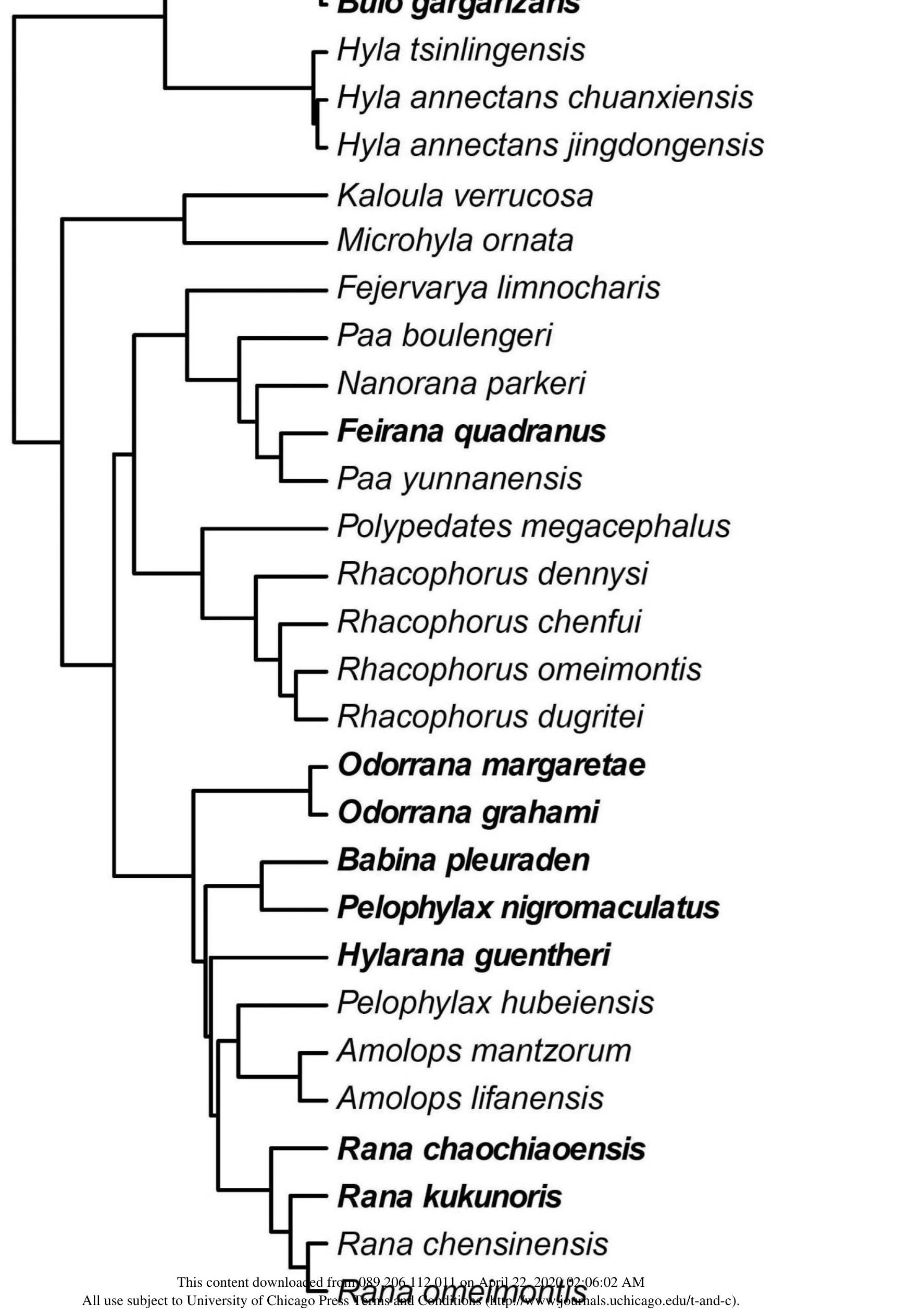


Supplementary file

\section{Relative brain size is predicted by the intensity of intrasexual competition in frogs}

Chun Lan Mai (麦春兰) $)^{1,2,3}$, Wen Bo Liao (廖文波 $)^{1,2,3, *}$, Stefan Lüpold ${ }^{4 \S}$, and Alexander Kotrschal $^{5 \S}$

${ }^{\S}$ These authors contributed equally to the project and manuscript preparation.

1: Key Laboratory of Southwest China Wildlife Resources Conservation (Ministry of

Education), China West Normal University, Nanchong, 637009, Sichuan, China

2: Key Laboratory of Artificial Propagation and Utilization in Anurans of Nanchong City,

China West Normal University, Nanchong, Sichuan, 637009, China

3: Institute of Eco-adaptation in Amphibians and Reptiles, China West Normal University, Nanchong, 637009, Sichuan, China

4: Department of Evolutionary Biology and Environmental Studies, University of Zurich, Winterthurerstrasse 190, 8057 Zurich, Switzerland

5: Zoological Institute, Stockholm University, 10691, Stockholm, Sweden

*Correspondence: Liaobo_0_0@126.com 


\section{Disentangling multiple selection pressures on male brain size}

In supplementary analyses, we examined in more detail the effects of the spawning-site density and operational sex ratio on relative male brain size. Specifically, independent analyses have linked variables such as age at sexual maturity, longevity, or the duration of the breeding season to variation in relative brain size of anurans (Luo et al. 2017; Yu et al. 2018). Since these variables are also associated with the spawning-site density, albeit using latitude rather than the duration of the breeding season itself (Cai et al. 2019), it is important to understand how these different effects are linked to one another. For example, it could be hypothesized that ecological and life-history variables explain variation in population density and structure, and that these latter variables then drive the evolution of relative brain size through competition among males over mates as described in the main text of our study. If so, our previous findings would reflect not direct but indirect effects mediated by population density and structure.

To disentangle these effects, we used phylogenetic confirmatory path analyses (von Hardenberg and Gonzalez-Voyer 2013) as implemented in the R package phylopath (van der Bijl 2018), based on pre-specified candidate path models (fig.S1). Due to considerable variance inflation caused by collinearity between longevity and the age at sexual maturity (VIF up to $>9$ ), such that all candidate models were highly rejected $(P<0.0004)$, and to avoid overly complex models given the relatively small sample size, we performed two separate analyses, using one or the other of these two variables, along with an approximated duration of the breeding season based on climatic variables near the given breeding locations (Cai et al. 2019), and the population variables examined in the present study. Phylogenetic confirmatory path analyses rank all candidate models based on their C-statistic Information Criterion ( $\mathrm{CICc}$ ) and average those with $\triangle \mathrm{CICc} \leq 2$ from the top model to examine the 
conditional independences of each model(von Hardenberg and Gonzalez-Voyer 2013; van der Bijl 2018).

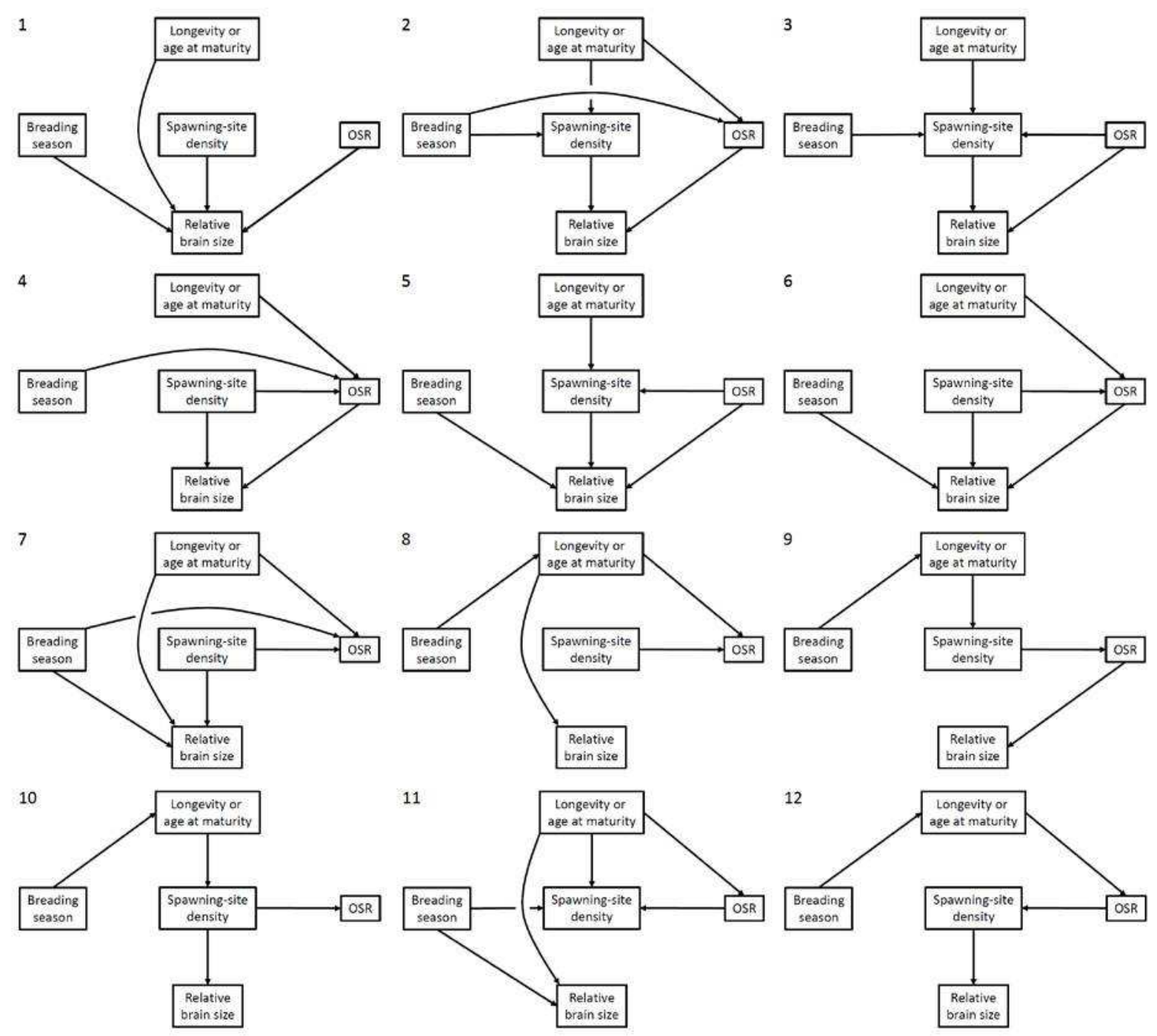

Figure S1: Directed acyclic graphs representing 12 candidate models that were compared to disentangle the relationships between six traits in anurans using phylogenetic confirmatory path analyses. Relative brain size was represented as residual brain size after removing variation in body size. 

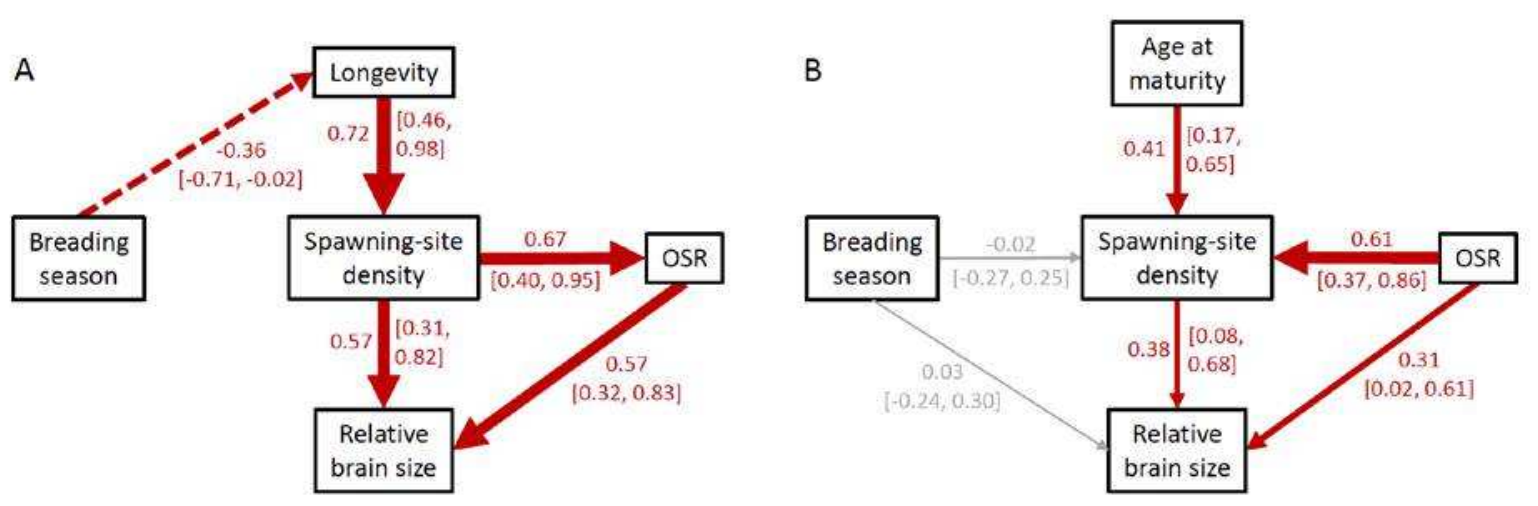

Figure S2: Visual representation of the averaged best-fitting path models ( $\mathrm{CICc} \leq 2)$ based on the directed acyclic graphs in fig.S1.Arrows reflect the direction of the path, and their line width is proportional to their standardized regression coefficients (adjacent to arrows, along with $95 \% \mathrm{CI}$ ). For red arrows, the 95\%CI of the coefficients excluded 0 (i.e., arrows are highly probable), for gray arrows it did not (i.e., arrows are uncertain). The dashed arrow indicates a negative effect. The coefficients and their 95\% CI are listed in tablesS1 (for A) and S2 (for B), respectively. Brain size was represented as residual brain size after removing variation in body size.

Combined, these results indicate that the most important variables explaining relative male brain size (at least among those examined here) are the density and operational sex ratio of the breeding aggregation, and that the previously documented effects of life history and seasonality on relative brain size (Luo et al. 2017; Yu et al. 2018) are at best indirect, mediated by population density and structure. These latter two traits seem to be dependent on one another, with cause and effect more difficult to separate (e.g., direction differs between panels A and B of fig. S2). One explanation is that an increasing population density might result in a more biased OSR (or vice versa) when the number of females at a pond is constrained by oviposition sites, or when females visit a pond asynchronously, but males aggregate and remain around the pond for extended periods. 
Table S1: Results of the different candidate models represented in fig. S1, using longevity as the life-history trait, ranked according to their CICc. The models with $\triangle \mathrm{CICc}<2$ are represented in bold and were used to calculate the average model (fig. S2A). $P$-values were calculated based on $\chi^{2}$ of the C-statistic with $k$ times 2 degrees of freedom. Models with $P<$ 0.05 are rejected (van der Bijl 2018).

\begin{tabular}{llllllll}
\hline Model & $\boldsymbol{k}$ & $\boldsymbol{q}$ & $\boldsymbol{C}$ & $\mathbf{C I C c}$ & $\Delta \mathbf{C I C c}$ & $\boldsymbol{w}_{\boldsymbol{i}}$ & $\boldsymbol{P}$ \\
\hline $\boldsymbol{m 1 0}$ & $\mathbf{6}$ & $\mathbf{9}$ & $\mathbf{1 2 . 8}$ & $\mathbf{3 9 . 8}$ & $\mathbf{0 . 0 0}$ & $\mathbf{0 . 6 1}$ & $\mathbf{0 . 3 8 1}$ \\
$\boldsymbol{m \boldsymbol { 9 }}$ & $\mathbf{6}$ & $\mathbf{9}$ & $\mathbf{1 3 . 9}$ & $\mathbf{4 0 . 9}$ & $\mathbf{1 . 0 2}$ & $\mathbf{0 . 3 7}$ & $\mathbf{0 . 3 1 0}$ \\
$m 5$ & 5 & 10 & 16.5 & 48.1 & 8.28 & 0.01 & 0.085 \\
$m 3$ & 5 & 10 & 16.9 & 48.5 & 8.66 & 0.01 & 0.076 \\
$m 12$ & 6 & 9 & 28.3 & 55.3 & 15.42 & 0.00 & 0.005 \\
$m 2$ & 4 & 11 & 19.5 & 56.2 & 16.33 & 0.00 & 0.012 \\
$m 4$ & 5 & 10 & 33.6 & 65.2 & 25.37 & 0.00 & $<0.001$ \\
$m 6$ & 5 & 10 & 34.8 & 66.4 & 26.52 & 0.00 & $<0.001$ \\
$m 11$ & 5 & 10 & 35.3 & 66.9 & 27.07 & 0.00 & $<0.001$ \\
$m 8$ & 6 & 9 & 47.2 & 74.2 & 34.37 & 0.00 & $<0.001$ \\
$m 7$ & 5 & 10 & 52.1 & 83.7 & 43.89 & 0.00 & $<0.001$ \\
$m 1$ & 6 & 9 & 64.5 & 91.5 & 51.62 & 0.00 & $<0.001$ \\
\hline
\end{tabular}

$k=$ number of independence claims; $q=$ number of parameters; $C=$ Fisher'sCstatistics; CICc= $\mathrm{C}$-statistic Information Criterion controlling for small sample size; $\Delta \mathrm{CICc}=$ difference in CICc from the best-fitting model; $w_{i}=$ CICc weights.

Table S2: Results of the different candidate models represented in fig. S1, using the age at sexual maturity as the life-history trait, ranked according to their CICc. The models with $\Delta \mathrm{CICc}<2$ are represented in bold and were used to calculate the average model (fig. S2B). $P$-values were calculated based on $\chi^{2}$ of the $\mathrm{C}$-statistic with $k$ times 2 degrees of freedom. Models with $P<0.05$ are rejected (van der Bij1 2018).

\begin{tabular}{llllllll}
\hline Model & $\boldsymbol{k}$ & $\boldsymbol{q}$ & $\boldsymbol{C}$ & $\mathbf{C I C c}$ & $\boldsymbol{\Delta C I C c}$ & $\boldsymbol{w}_{\boldsymbol{i}}$ & $\boldsymbol{P}$ \\
\hline $\boldsymbol{m 5}$ & $\mathbf{5}$ & $\mathbf{1 0}$ & $\mathbf{1 3 . 8}$ & $\mathbf{4 5 . 4}$ & $\mathbf{0 . 0 0}$ & $\mathbf{0 . 4 8}$ & $\mathbf{0 . 1 8 4}$ \\
$\boldsymbol{m 3}$ & $\mathbf{5}$ & $\mathbf{1 0}$ & $\mathbf{1 3 . 9}$ & $\mathbf{4 5 . 5}$ & $\mathbf{0 . 1 1}$ & $\mathbf{0 . 4 6}$ & $\mathbf{0 . 1 7 9}$ \\
$m 9$ & 6 & 9 & 23.3 & 50.3 & 4.97 & 0.04 & 0.025 \\
$m 10$ & 6 & 9 & 25.1 & 52.1 & 6.73 & 0.02 & 0.015 \\
$m 4$ & 5 & 10 & 23.4 & 54.9 & 9.59 & 0.00 & 0.009 \\
$m 12$ & 6 & 9 & 29.1 & 56.1 & 10.77 & 0.00 & 0.004 \\
$m 6$ & 5 & 10 & 24.7 & 56.3 & 10.96 & 0.00 & 0.006 \\
$m 11$ & 5 & 10 & 31.5 & 63.1 & 17.70 & 0.00 & $<0.001$ \\
$m 2$ & 4 & 11 & 27.8 & 64.5 & 19.12 & 0.00 & 0.001 \\
$m 8$ & 6 & 9 & 41.7 & 68.7 & 23.33 & 0.00 & $<0.001$ \\
$m 1$ & 6 & 9 & 43.7 & 70.7 & 25.40 & 0.00 & $<0.001$ \\
$m 7$ & 5 & 10 & 40.9 & 72.5 & 27.17 & 0.00 & $<0.001$ \\
\hline
\end{tabular}




\section{References}

Cai, Y. L., C. L. Mai, and W. B. Liao. 2019. Frogs with denser group-spawning mature later and live longer. Scientific Reports 9:13776.

Luo, Y., M. J. Zhong, Y. Huang, F. Li, W. B. Liao, and A. Kotrschal. 2017. Seasonality and brain size are negatively associated in frogs: Evidence for the expensive brain framework. Scientific Reports 7:1-9.

van der Bijl, W. 2018. phylopath: Easy phylogenetic path analysis in R. PeerJ 6:e4718.

von Hardenberg, A., and A. Gonzalez-Voyer. 2013. Disentangling evolutionary cause-effect relationships with phylogenetic confirmatory path analysis. Evolution 67:378-387.

Yu, X., M. J. Zhong, D. Y. Li, L. Jin, W. B. Liao, and A. Kotrschal. 2018. Large-brained frogs mature later and live longer. Evolution 72:1174-1183. 